\title{
Automatic Load Sharing of Distribution Transformers to Reduce Over all Losses in Distribution network.
}

\author{
Ravikumar $\mathrm{V}^{1, *}$, Ranjith $\mathrm{S}^{2}$ and Bhavyasree $\mathrm{T}^{3}$ \\ ${ }^{1}$ Department of Electrical and Electronics Engineering, Siddaganga Institute of Technology, Tumakuru, Karnataka, India \\ ${ }^{2}$ Department of Electrical and Electronics Engineering, Siddaganga Institute of Technology, Tumakuru, Karnataka, India \\ ${ }^{3}$ Department of Master of Computer application, Tumkur University, Tumakuru, Karnataka, India
}

\begin{abstract}
An increase in the development of Industries and rapid growth in the population has led to an increase in the power demand in the distribution network. With these increased needs, the existing distribution transformer have become overloaded conditions. Due to overload on the transformer, the efficiency and power factor drops and also it led to increase in the transformer voltage regulation and windings get overheated. This paper presents a novel topology called transformer auto stop-start that will automatically energise and de-energise, one pair of transformers at a $\mathrm{kV} / \mathrm{V}$ Distribution network. In this way, the proposed technique reduces overall electric losses. Performance of transformer under different load conditions are illustrated by simulation.
\end{abstract}

Keywords: Transformer overload, Distribution network, MATLAB/Simulink

\section{Introduction}

Transformer is a static device, that transfers alternating voltage from one electrical network to another electrical network by the principal of mutual induction. Distribution transformers are also called as heart of the power system and they place an important role in power system [1].

Now a days an increase in the development of industries and rapid growth in the population have led to an increase the demand on electrical power generation system. The increase in the needs of the consumers, the existing distribution network have become overloaded [2]. Due to overload on the transformer, the voltage regulation of transformer increases, the windings get over heated and also the efficiency drops [3]. These problems can be overcome by connecting the transformers in parallel [4-6]. The parallel operation reduces the burden on single transformer; thus, it increases the efficiency and reduces winding failure [7]. The main draw back of parallel operation was to operate with same rating of transformer [8-9]. This paper describes the operation of two different kVA transformers under different load conditions.

This paper is categorised into six parts: I Introduction, II proposed methodology, III Simulation of proposed technique, IV Simulation Results, V Comparison of parallel operation and proposed technique, VI Presents the conclusion of the proposed technique.

\section{Proposed Methodology}
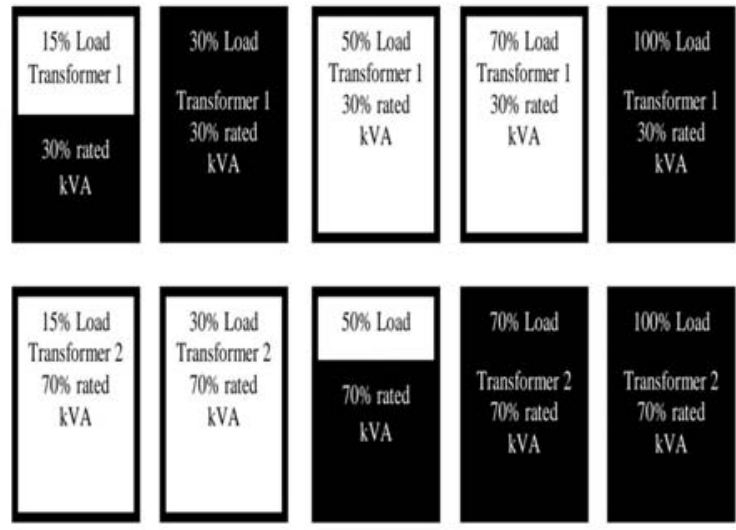

Fig.1. Load sharing of two different rating transformers

The working of two different kVA transformer operating under Load is as shown in Fig.1. In this methodology, the transformer will automatically energise and de-energise one of a pair of transformer at a $\mathrm{kV} / \mathrm{V}$ Distribution network. The open circuit and short circuit results of $(150 \mathrm{kVA}+63 \mathrm{kVA}), 11 \mathrm{kV} / 430 \mathrm{~V}$, Transformers are tabulated in the Table 1.

Table 1. OC and SC results of (150kVA+63kVA), $11 \mathrm{kV} / 430 \mathrm{~V}$, transformers

\begin{tabular}{|c|c|c|c|c|c|}
\hline $\begin{array}{c}\text { Transformer } \\
(\mathrm{kVA})\end{array}$ & $\begin{array}{c}\text { Load } \\
(\%)\end{array}$ & $\begin{array}{c}\text { Primary } \\
\text { current }\end{array}$ & $\begin{array}{c}\text { No- load } \\
\text { loss (W) }\end{array}$ & $\begin{array}{c}\text { Load } \\
\text { loss }\end{array}$ & $\begin{array}{c}\text { Total } \\
\text { losses }\end{array}$ \\
\hline
\end{tabular}

\footnotetext{
* Corresponding author: ravikumarv@sit.ac.in
} 


\begin{tabular}{|c|c|c|c|c|c|}
\hline & & $(\mathrm{A})$ & & $(\mathrm{W})$ & $(\mathrm{W})$ \\
\hline 63 & 0 & 0 & 165 & 0 & 165 \\
\hline 63 & 10 & 1.122 & 165 & 18 & 283 \\
\hline 63 & 20 & 2.224 & 165 & 464 & 629 \\
\hline 150 & 30 & 3.336 & 270 & 372 & 642 \\
\hline 150 & 40 & 4.448 & 270 & 662 & 932 \\
\hline 150 & 50 & 5.56 & 270 & 1034 & 1304 \\
\hline $150+63$ & 60 & 6.672 & 435 & 1097 & 1532 \\
\hline $150+63$ & 70 & 7.784 & 435 & 1493 & 1928 \\
\hline $150+63$ & 80 & 8.896 & 435 & 1950 & 2385 \\
\hline
\end{tabular}

\section{Simulation of Proposed Technique}

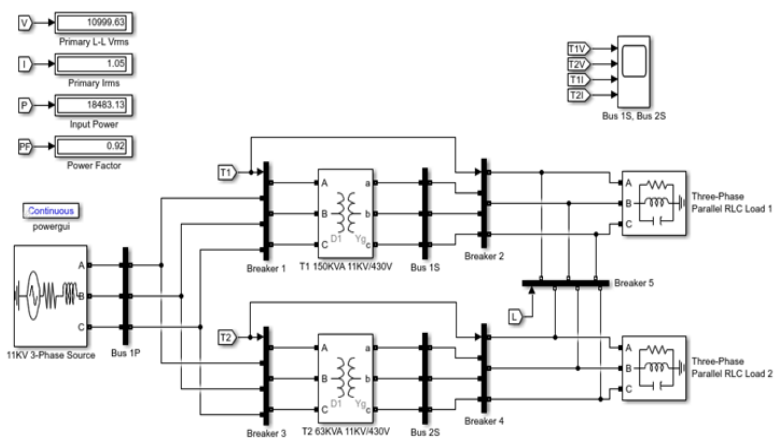

Fig.2. Simulation circuit diagram of $150 \mathrm{kVA}$ and $63 \mathrm{kVA}$ system

The circuit diagram of a $3-\phi,(150 \mathrm{kVA}+63 \mathrm{kVA})$, $11 \mathrm{kV} / 430 \mathrm{~V}$ distribution system is as shown in Fig.2. Both the transformer primary are connected to $11 \mathrm{kV}$ bus through Circuit breaker. Circuit breaker are used to make or break the transformer in the circuit. The current and voltage sensors are used to measures the designed parameters. Based on the load condition, the Logic circuit will monitor the opération of Transformers.

\section{Simulation results of proposed technique.}

\subsection{Results of (150kVA+63 kVA) transformer} system for a load of $20 \mathrm{~kW}$.

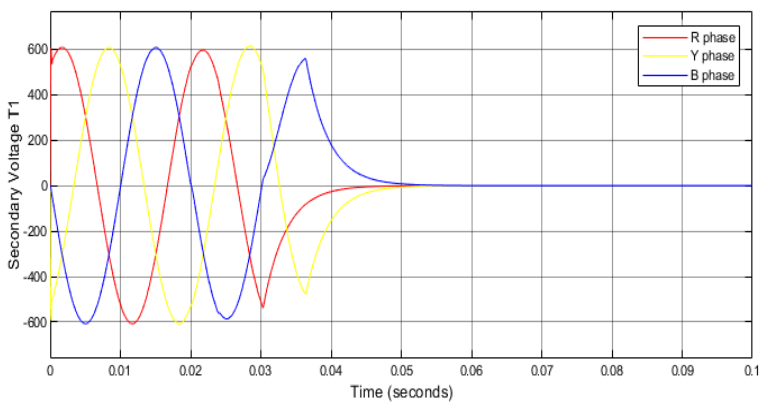

Fig.3. (a). Secondary voltage of transformer $1\left(\mathrm{~T}_{1}\right)$

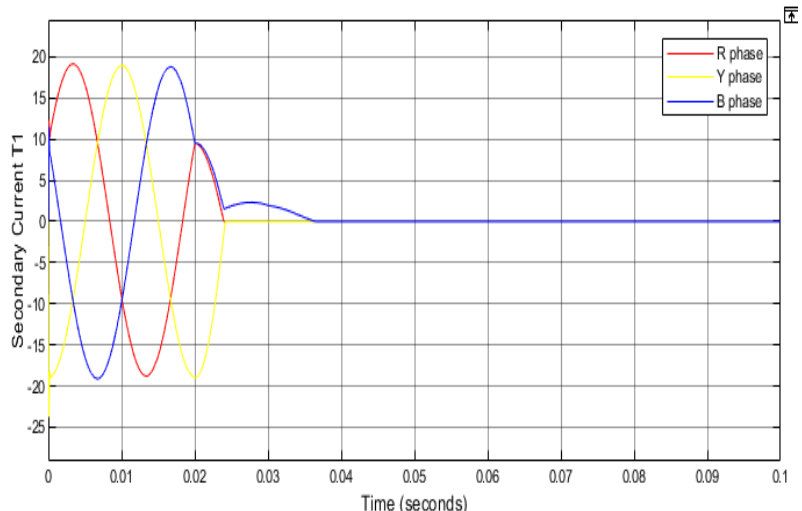

Fig.3 (b). Secondary Current of transformer $1\left(T_{1}\right)$

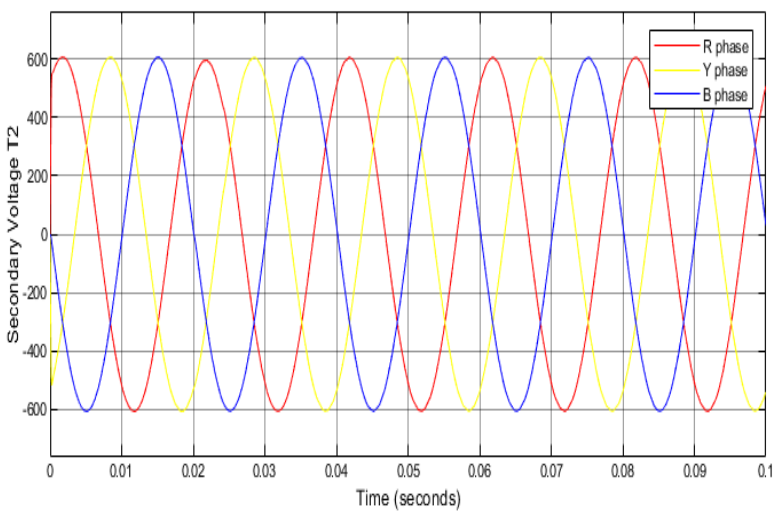

Fig.3. (c). Secondary voltage of Transformer $2\left(\mathrm{~T}_{2}\right)$

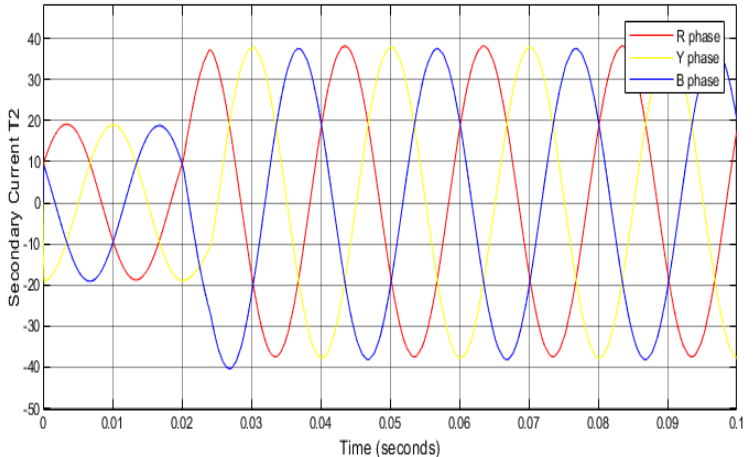

Fig.3. (d). Secondary Current of Transformer $2\left(\mathrm{~T}_{2}\right)$

Fig.3. Output waveform of $(150 \mathrm{kVA}+63 \mathrm{kVA})$ system for a load of $20 \mathrm{~kW}$

The results of $(150 \mathrm{kVA}+63 \mathrm{kVA})$ distribution transformer system for a load of $20 \mathrm{~kW}$ are shown in Fig.3. The secondary voltage of transformer $T_{1}$ and transformer $\mathrm{T}_{2}$ are shown in Fig.3.(a) and Fig.3.(c)

The secondary current of transformer $T_{1}$ and $T_{2}$ are shown in Fig.3.(b) and Fig.3.(d). In this case, a load of $20 \mathrm{~kW}$ is applied to the circuit. A applied load current is less than the rated current of transformer $\mathrm{T}_{2}$. The logic circuit given a signal to turn-off $150 \mathrm{kVA}$ transformer $T_{1}$. Now the transformer $T_{1}$ is isolated and transformer $\mathrm{T}_{2}$ alone supplies the load until any control signal changes from the logic circuit. The output of $20 \mathrm{~kW}$ load is shown in the Fig.4. 


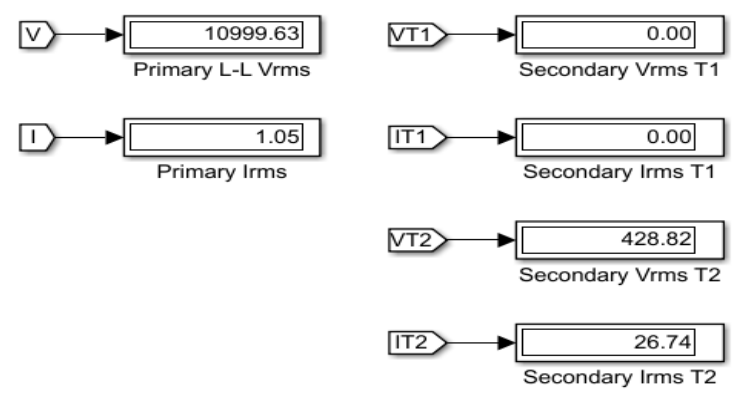

Fig.4. Output of $20 \mathrm{~kW}$ load

\subsection{Results of $(150 \mathrm{kVA}+63 \mathrm{kVA})$ transformer} system for a load of $80 \mathrm{~kW}$.

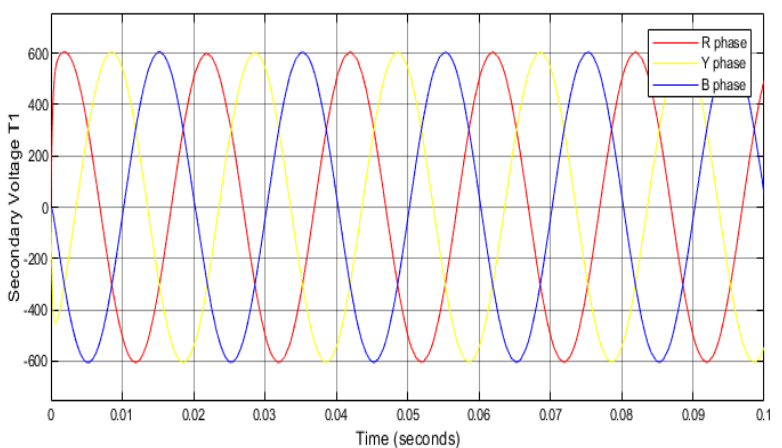

Fig.5.(a) Secondary voltage of Transformer $\left(T_{1}\right)$ for a load of $80 \mathrm{~kW}$

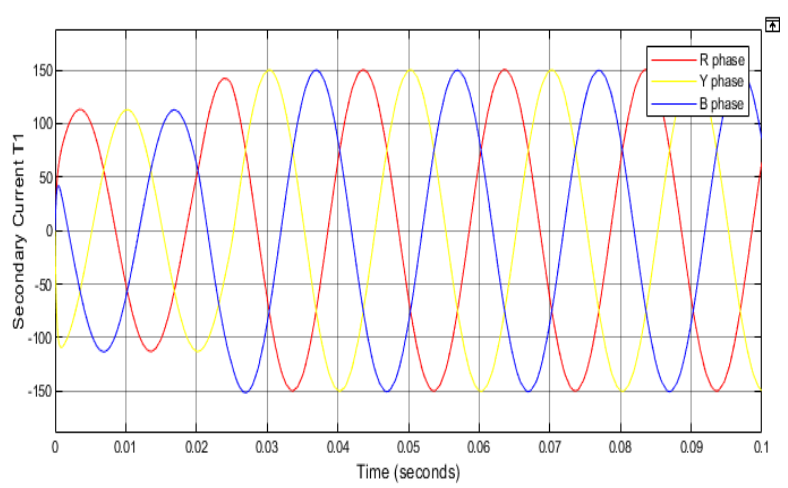

Fig.5. (b) Secondary current of Transformer $\left(T_{1}\right)$ for a load of $80 \mathrm{~kW}$

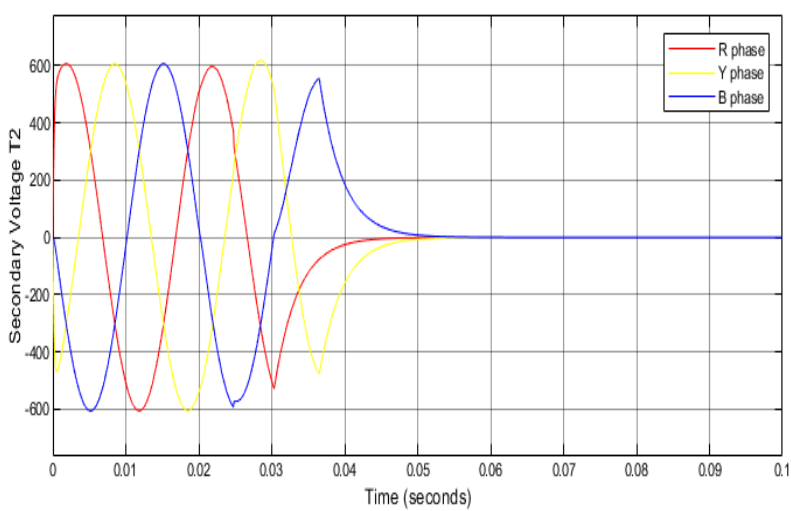

Fig.5. (c) Secondary voltage of Transformer $\left(\mathrm{T}_{2}\right)$ for a load of $80 \mathrm{~kW}$

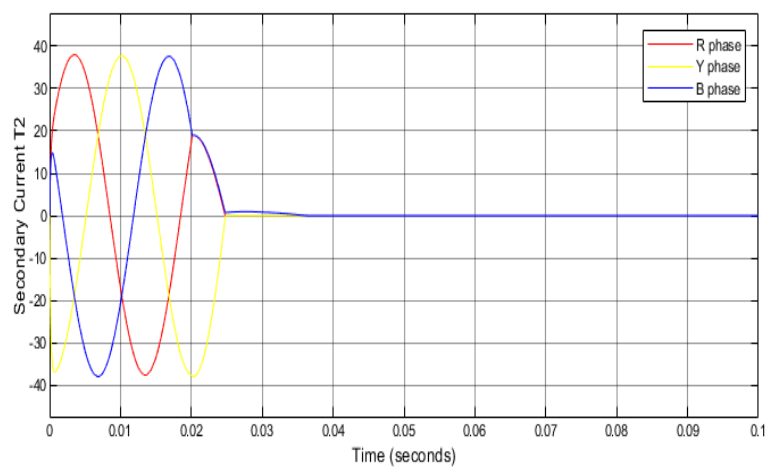

Fig.5. (d) Secondary Current of Transformer $\left(\mathrm{T}_{2}\right)$ for a load of $80 \mathrm{~kW}$

Fig.5. Output waveform of (150kVA+63 kVA) system for load of $80 \mathrm{~kW}$

The results of $(150 \mathrm{kVA}+63 \mathrm{kVA})$ distribution transformer system for a load of $80 \mathrm{~kW}$ are shown in Fig.5. The secondary voltage of transformer $T_{1}$ and transformer $T_{2}$ are shown in Fig.5.(a) and Fig.5.(c)

The secondary current of transformer $T_{1}$ and $T_{2}$ are shown in Fig.5.(b) and Fig.5.(d). In this case, a load of $80 \mathrm{~kW}$ is applied to the circuit. A applied load current is less than the rated current of transformer $T_{1}$ and greater than the rated current of transformer $T_{2}$. The logic circuit given a signal to turn-off 63 kVA transformer $T_{2}$. Now the transformer $T_{2}$ is isolated and transformer $T_{1}$ alone supplies the load until any control signal changes from the logic circuit.

The output of $80 \mathrm{~kW}$ load is shown in the Fig. 6

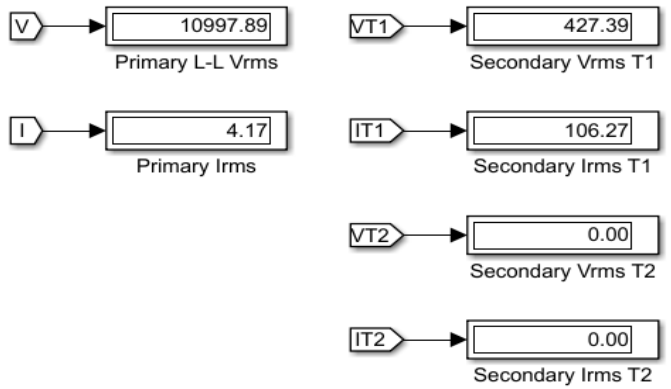

Fig.6. Output of $80 \mathrm{~kW}$ load

\subsection{Results of (150kVA+63 kVA) transformer system for a load of $170 \mathrm{~kW}$.}

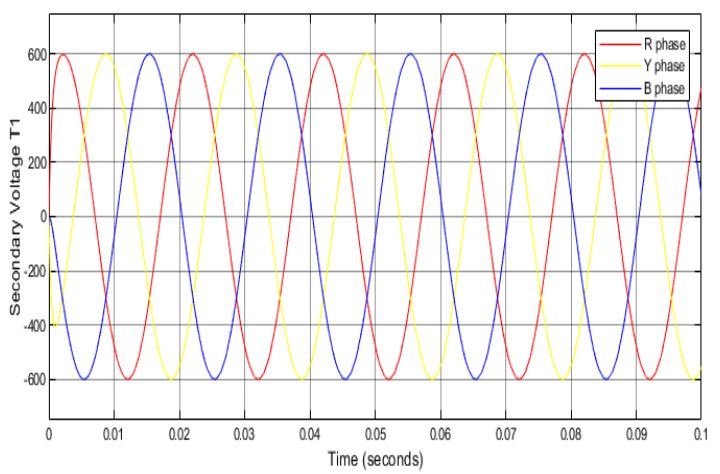

Fig.7 (a) Secondary voltage of Transformer $\left(T_{1}\right)$ for a load of $170 \mathrm{~kW}$ 


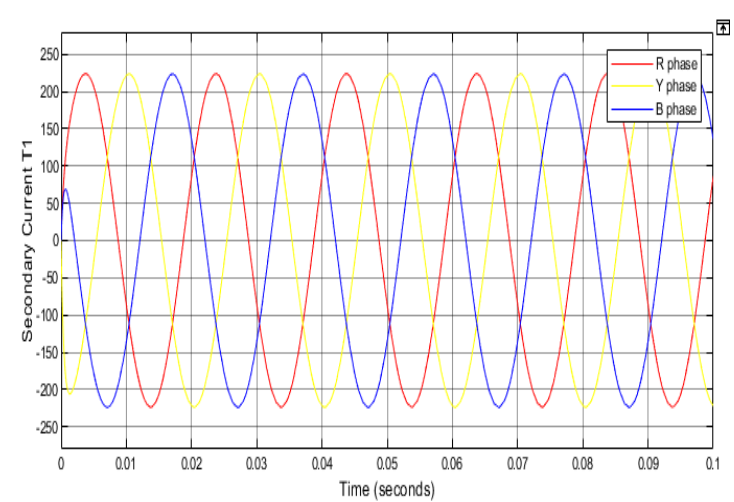

Fig.7 (b) Secondary Current of Transformer $\left(T_{1}\right)$ for a load of $170 \mathrm{~kW}$

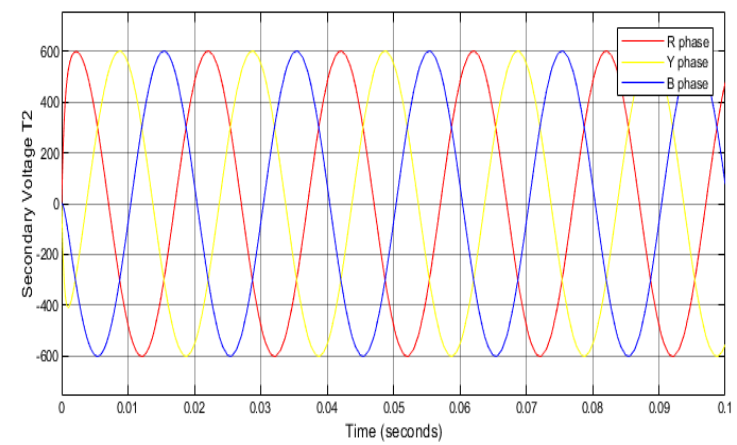

Fig.7 (c) Secondary voltage of Transformer $\left(\mathrm{T}_{2}\right)$ for a load of $170 \mathrm{~kW}$

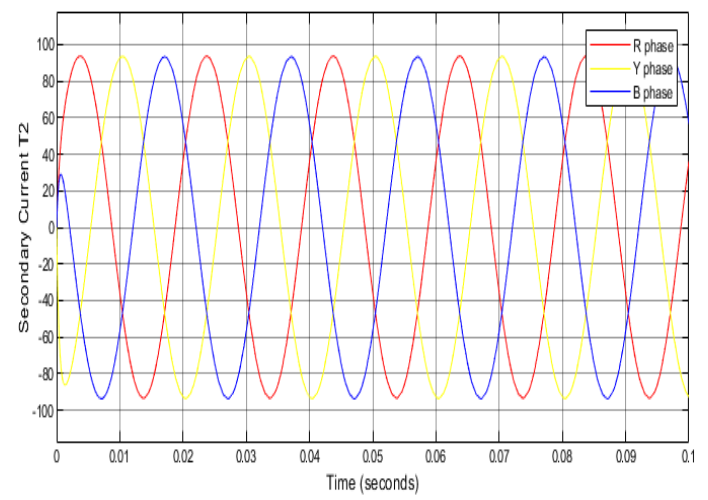

Fig.7. (d) Secondary Current of Transformer $\left(\mathrm{T}_{2}\right)$ for a load of $170 \mathrm{~kW}$

Fig.7.Output waveform of $(150 \mathrm{kVA}+63 \mathrm{kVA})$ system for a load of $170 \mathrm{~kW}$

The results of $(150 \mathrm{kVA}+63 \mathrm{kVA})$ distribution transformer system for a load of $170 \mathrm{~kW}$ are shown in Fig.7. The secondary voltage of transformer $T_{1}$ and transformer $\mathrm{T}_{2}$ are shown in Fig.7.(a) and Fig.7.(c). The secondary current of transformer $T_{1}$ and $T_{2}$ are shown in Fig.7.(b) and Fig.7.(d). In this case, a load of $170 \mathrm{~kW}$ is applied to the circuit. A applied load current is grater than individual rated current of transformer $T_{1}$ and transformer $\mathrm{T}_{2}$. Both the Transformers are operated.

\section{5. comparison of proposed technique with parallel operation}

The transformer losses under diffèrent conditions are as shown in Fig.8. The maximum loading of transformer is limited to $80 \%$. If the load exceed, results in more heat dissipation in the transformer winding and also it reduces over all life of the transformer. In the proposed technique, at any instant of time transformer will automatically energise and de-energise, one of a pair of transformer at a $\mathrm{kV} / \mathrm{V}$ Distribution network.

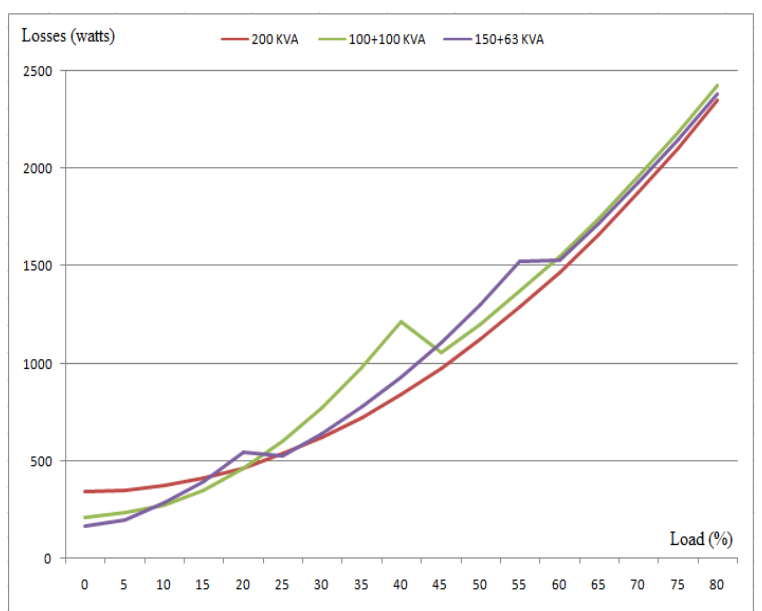

Fig.8. Graphical representation of transformer losses

It improve the system efficiency and reduces over all losses. From the graph it is clear that, the combination of two different transformer (150kVA+63kVA) system will results in less losses comparing with the two 100kVA transformer system.

\section{Conclusion}

Transformers the most generic and expensive equipment of the transmission and distribution network. Losses of the transformer mainly depends on rating and size of the transformer. Most of the villages and cities were suffering with electric instructions and it was due to transformer failure. In this paper, the system automatically couples and decouples the switch to share transformer loads and it was successfully achieving the load sharing of two different $(150 \mathrm{kVA}+63 \mathrm{kVA})$ transformer under load conditions.

\section{References}

1. Ashish R. Ambalkar, Nitesh M. Bhoyar, Vivek V. Badarkhe and Vivek B. Bathe, "Automatic Load Sharing of Transformers", International Journal for Scientific Research \& Development, Volume 2, Issue 12, pp. 739741,2015

2. "Electricity Distribution Units and Loss Percentages Summary - Factsheet," Ofgem, London, UK, Aug.2010.

3. Kamel R, Kermanshahi B. 'Optimal size and location of distributed generations for minimizing power losses in a primary distribution network', Sci Iranica. 2009;16(2):137

4. M. Kraiczy, T. Stetz, 'Parallel Operation of Transformers with On Load Tap Changer and Photovoltaic Systems with Reactive Power Control' IEEE Transactions on Smart Grid,2017. 
5. Haibo Liu, Chengxiong Mao, 'Parallel Operation of Electronic Power Transformer and Conventional Transformer', DRPT2008 6-9 April 2008

6. Dan Wang, Chengxiong Mao, Jiming Lu, "Parallel operation of electronic power transformer," Automation of Electric Power Systems, 2005, 29(16): 66-71.

7. David D. Shipp, PE and Thomas J. Dionise, PE, 'Switching Transients, Transformer Failures and Practical Solutions', IEEE Houston Section Continuing Education on Demand 2016.

8. Abraham Hizkiel Nebey, 'Automatic load sharing of distribution transformer for overload protection', Nebey BMC Res Notes (2020)

9. S.M. Bashi, N.Mariun and A. Rafa, 'Power Transformer protection using Microcontroller based relay', Journal of Applied Sciences · December 2007 